Archive for

Organic Chemistry

Arkivoc 2020, part ii, 34-52

\title{
Mechanisms of the formation of imines in aqueous solution and the effect of the
}

\section{$\mathrm{pH}:$ a theoretical analysis}

\author{
Virginia C. Rufino and Josefredo R. Pliego Jr*
}

Departamento de Ciências Naturais, Universidade Federal de São João del-Rei

36301-160, São João del-Rei, MG, Brazil

Email:pliego@ufsj.edu.br

\section{Dedicated to Professor Jose M. Riveros for his outstanding contribution to chemistry}

Received 11-02-2019

Accepted 01-05-2020

Published on line $01-17-2020$

\section{Abstract}

Theoretical modeling of the formation imines in aqueous medium from the reaction of amines with aldehydes is difficult due to formation of charged species, zwitterions, acid-base equilibria and a substantial solvent effect. In this work, a model reaction of methylamine with acetaldehyde was investigated involving neutral and ionic pathways, influence of the $\mathrm{pH}$ and different approaches for treating the solvent effect. We have found a mechanism able to explain the fast kinetics of this system, involving the zwitterion formation followed by its isomerization to the carbinolamine and an easy iminium ion formation via an ionic elimination mechanism.

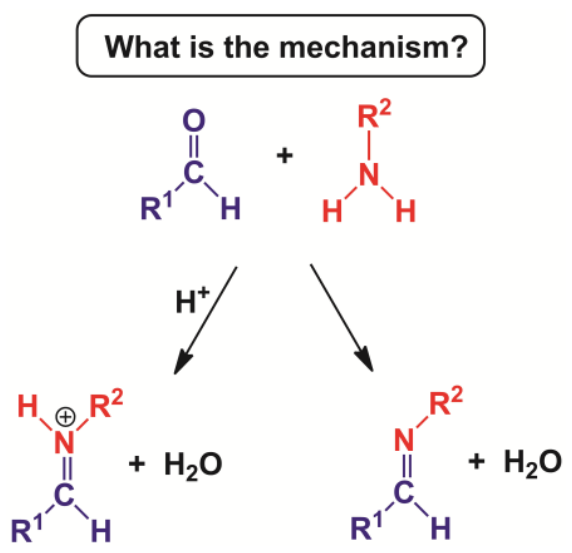

Keywords: Iminium mechanism, Protic solvent, Solvent effect, SMD, cluster-continuum 


\section{Introduction}

Imines are important intermediates in the synthesis of chiral molecules ${ }^{1-4}$ and are widely used as ligands in organometallic chemistry. ${ }^{5}$ This class of compounds can be obtained by reacting aldehydes and ketones with primary amines. ${ }^{6-8}$ Both water and organic solvents can be used as reaction medium. In the case of aqueous medium, because this reaction is an equilibrium and amines can be protonated, quantitative formation of the final product in aqueous solution depends of the aldehyde-amine pair and the $\mathrm{pH}$ of the medium. Usually, the reaction takes place in two main steps: the first step is the formation of carbinolamine intermediate, and the second step is the dehydration of this intermediate, generating the imine (Scheme 1).

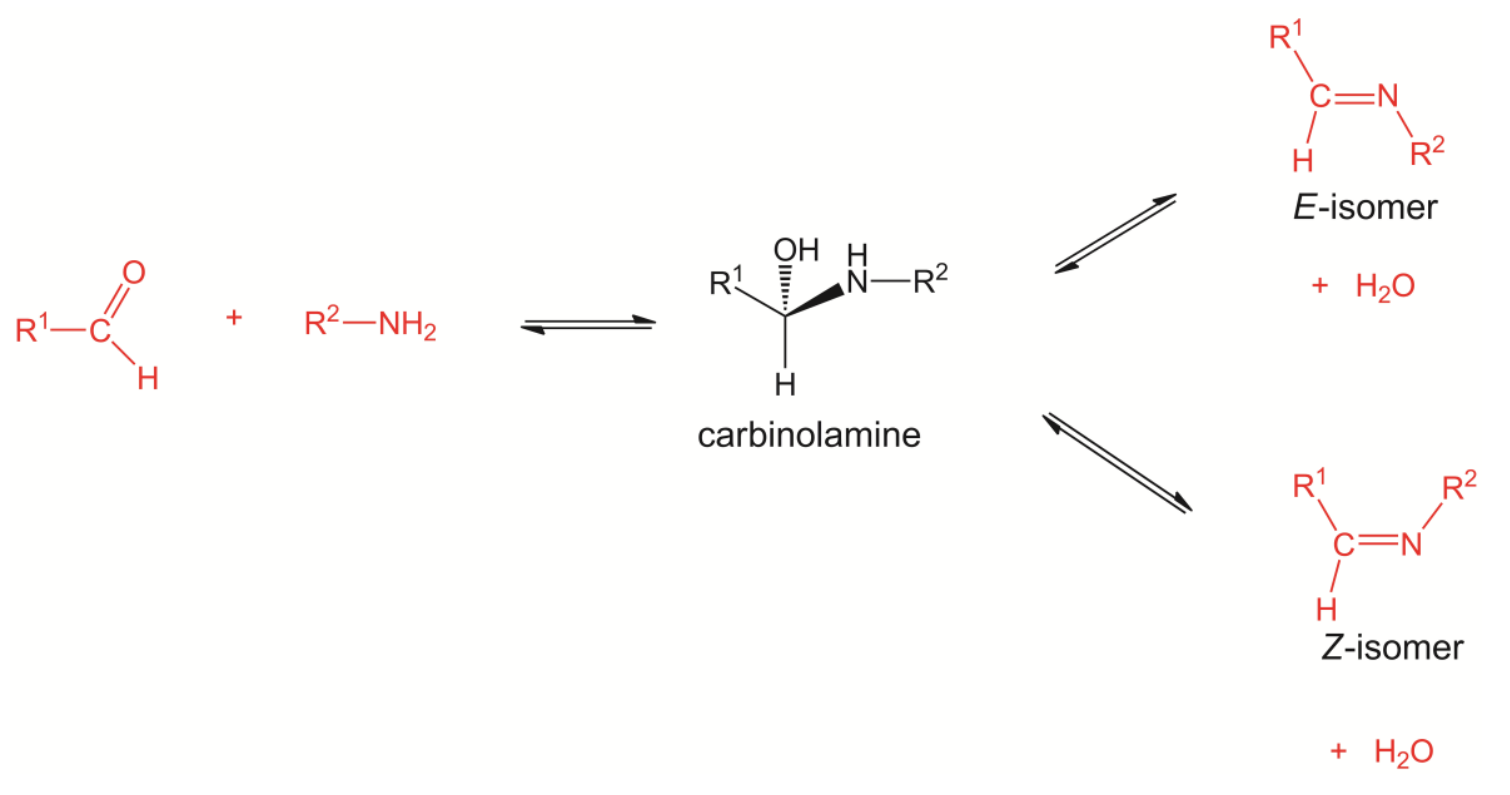

Scheme 1. Main steps for imine formation from alkylamine addition to aldehyde.

The mechanism and kinetics of this reaction has been experimentally investigated by Cordes and Jencks ${ }^{9}$ and also by Hine and coworker. ${ }^{10-11}$ The reaction proceeds quickly in aqueous solution. For example, in the addition of methylamine to isobutyraldehyde, the experiments have indicated that the rate-determining step in a medium with $\mathrm{pH}=10.1$ to 11.5 is the carbinolamine decomposition with a rate constant of $6.2 \mathrm{~s}^{-1}$, which translate to a $\Delta \mathrm{G}^{\ddagger}$ barrier of $16.4 \mathrm{kcal} \mathrm{mol}^{-1}$. The equilibrium constant for the carbinolamine formation was determined as $8.5 \mathrm{M}^{-1}$, leading to a $\Delta \mathrm{G}$ of $-1.3 \mathrm{kcal} \mathrm{mol}^{-1}$. The influence of the $\mathrm{pH}$ of the medium is also interesting. In the experimental studies of the reaction of $p$-chlorobenzaldehyde with aniline, the reaction rate increases with the $\mathrm{pH}$ and reaches the maximum value at $\mathrm{pH}$ close to 4 . The carbinolamine formation becomes the rate-determining step in low $\mathrm{pH}$. Equilibrium constants for several imines formation from aldehydes and amines were reported more recently. ${ }^{12}$

There are some theoretical studies on the mechanism of this kind of reaction reported in the literature. ${ }^{13-18}$ Nevertheless, these studies do not provide a complete explanation of this system in aqueous medium. The interesting study by Hall and Smith on methylamine addition to formaldehyde have indicated that water molecules can catalyze this condensation reaction. ${ }^{13-14}$ In the first reaction step, they have found that two explicit water molecules leads to zwitterion formation, followed by isomerization to carbinolamine with very low activation barrier of $3.5 \mathrm{kcal} \mathrm{mol}^{-1}$. In the second step, elimination of water, two water molecules also participate in the transition state and the barrier becomes $26.7 \mathrm{kcal} \mathrm{mol}^{-1}$, indicating that the second step is 
rate-determining. In this point, we should emphasize that those authors have reported enthalpy profiles and they are considering the reactants-water cluster as the reference point for calculating barriers. In order to obtain theoretical reaction kinetics, the procedure would be considering all the species free to move in the solution for the calculation of the Gibbs free energy barrier. ${ }^{19}$ Furthermore, the calculated barrier in the carbinolamine dehydration step is $10 \mathrm{kcal} \mathrm{mol}^{-1}$ above of the experimental value for a similar system. ${ }^{10}$

Szefczyk et al. reported the reaction between methylamine and acetaldehyde at B3LYP level. ${ }^{15}$ Solvent effect was included through just adding one explicit water and free energies were not provided. In addition, their barriers were too high and not able to explain such easy reaction. Erdtman and coworkers have also investigated imine formation from alkylamine addition to aldehyde. ${ }^{16}$ The catalytic effect of explicit water in the reaction was also reported and acid medium effect was explored. Similar to Smith and Hall study, their analysis considers clusters involving the reactants and water and no kinetic model comparable to experimental data was provided.

The aim of this study is to provide a theoretical reaction mechanism with reaction steps in quantitative agreement with experimental $\Delta G$ values of a model reaction: methylamine addition to acetaldehyde in aqueous solution. In addition, to evaluate the influence of the $\mathrm{pH}$. The complete mechanism explored in this work is presented in the Scheme 2.

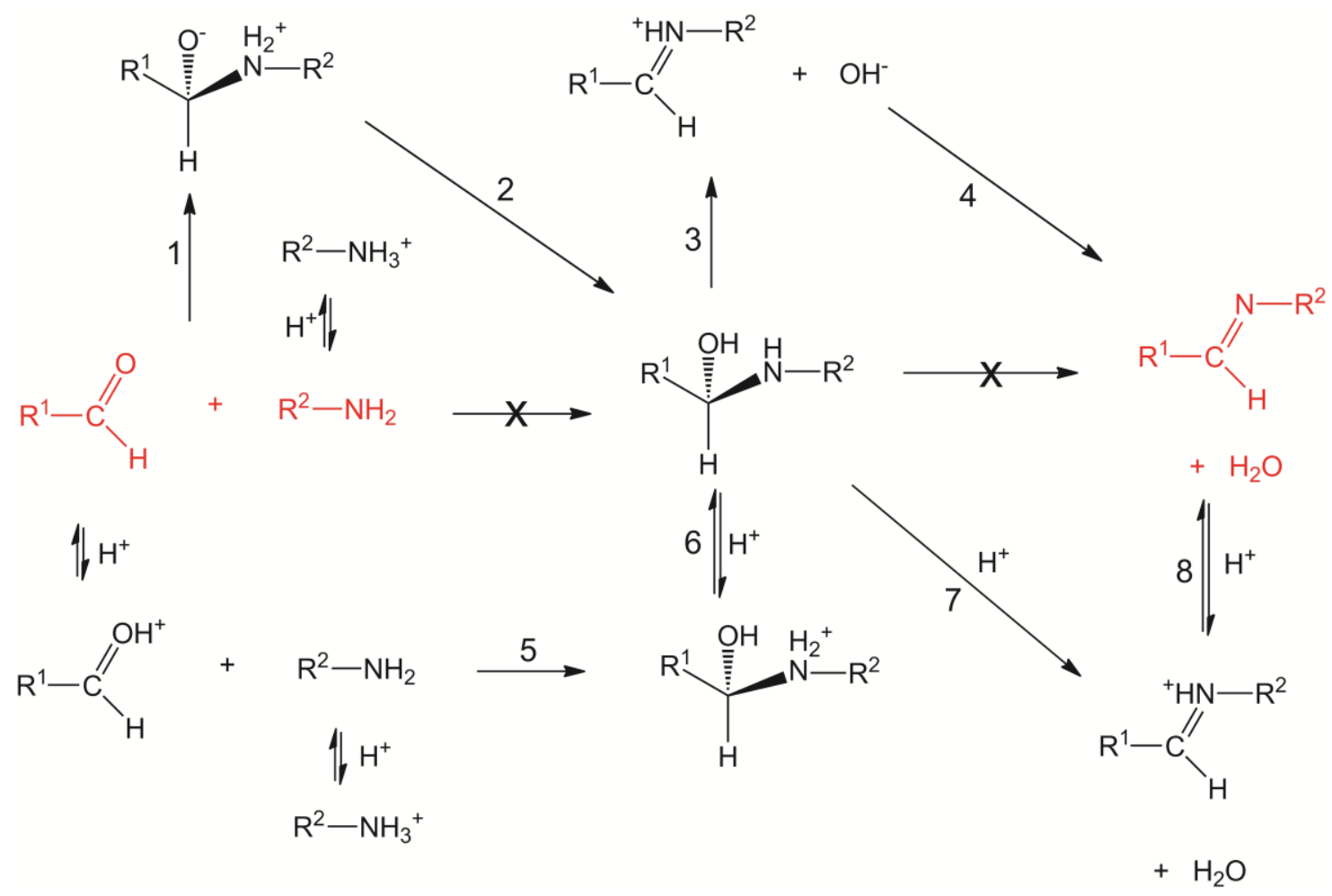

Scheme 2. General mechanism for imine formation in neutral, acid and basic medium. Only the $E$-imine formation is presented. All the steps are equilibria and the double arrow indicates that protonation/deprotonation equilibria are considered very fast. 


\section{Results and Discussion}

\section{Electronic structure calculations with continuum solvation model}

Geometry optimization and harmonic vibrational frequency calculations were performed at SMD/X3LYP/def2SVP (ma-def2-SVP basis set for oxygen and nitrogen atoms) level of theory. ${ }^{20-24}$ Single-points energy calculations were performed with the M06-2X25 functional with the def2-TZVPP (ma-def2-TZVPP for oxygen and nitrogen) basis set to obtain more accurate values for electronic energy ${ }^{22-24}$. In addition, solvation free energy was also obtained by single-point calculations performed at SMD/X3LYP/def2-SVP (ma-def2-SVP basis set for oxygen and nitrogen atoms) level of theory. Finally, solution phase free energy was obtained by using a composite procedure given by the relation:

$\mathrm{G}_{\text {sol }}(\mathrm{X})=\mathrm{E}_{\mathrm{el}}(\mathrm{X})+\mathrm{G}_{\mathrm{n}}(\mathrm{X})+\Delta \mathrm{G}_{\text {solv }}(\mathrm{X})+1.89 \mathrm{kcal} \mathrm{mol}^{-1}$

Where $G_{\text {sol }}$ refers to solution phase free energy, $E_{\text {el }}$ refers to electronic energy obtained by the M06-2X method, $G_{n}$ refers to the nuclear contributions to translational, vibrational and rotational motions obtained through frequency calculations at SMD/X3LYP/def2-SVP (ma-def2-SVP for $\mathrm{O}$ and $\mathrm{N}$ atoms) level of theory and $\Delta G_{\text {solv }}$ refers to solvation free energy, obtained at the same level of theory previously mentioned. The 1.89 $\mathrm{kcal} \mathrm{mol}^{-1}$ is related to correction of standard state of $1 \mathrm{~atm}$ to $1 \mathrm{~mol} \mathrm{~L}^{-1}$, adequate for reporting liquid phase processes. Further, in the case of water, we have used the standard state of pure liquid water and in this case the free energy becomes:

$\mathrm{G}_{\text {liq }}\left(H_{2} \mathrm{O}\right)=\mathrm{E}_{\text {el }}\left(H_{2} \mathrm{O}\right)+\mathrm{G}_{\mathrm{n}}\left(H_{2} \mathrm{O}\right)+\Delta \mathrm{G}_{\text {solv }}\left(H_{2} \mathrm{O}\right)+1.89 \mathrm{kcal} \mathrm{mol}^{-1}+R T \ln \left[\mathrm{H}_{2} \mathrm{O}\right]$

All the calculation were done with the Orca 4 program. ${ }^{26-27}$

\section{Calculation of $\mathrm{pK}_{\mathrm{a}}$}

In some steps involved of the mechanisms studied in the present work was necessary to perform calculations to obtain pKa values of some species. Thus, we have used a proton exchange scheme with a reference species, whose structure is close to the species studied in order to reduce the error associated with the solvent effect. This approach has been discussed in a previous work of our group. ${ }^{28-30}$ Thus, the solution phase free energy involved in proton exchange reaction (eq. 3) is calculated by theoretical methods described in the previous section. The obtained free energy is used in equation (4) together with the experimental pKa of a reference species. Such procedure usually leads to reliable free energies of reaction as well as pKa values.

$\mathrm{BH}^{+}+\operatorname{Ref} \rightarrow \mathrm{RefH}^{+}+\mathrm{B}$

$p K_{a}\left(B H^{+}\right)=\frac{\Delta G_{\text {sol }}}{R \operatorname{Rin}(10)}+p K_{a}\left(R e f H^{+}\right)$

Once the pKa is obtained, the $\Delta \mathrm{G}$ for some deprotonation reaction can be obtained by:

$$
\begin{aligned}
& \mathrm{BH}^{+} \rightarrow \mathrm{B}+\mathrm{H}^{+} \\
& \Delta G_{\text {desp }}=R T \cdot \ln (10) \cdot p K_{a}
\end{aligned}
$$




\section{Solvation free energy by the cluster-continuum static approximation}

The formation of charged species in liquid phase has a substantial solvent effect, difficult to be described by pure continuum solvation models. An improved procedure for solvation calculations is the use of hybrid discrete-continuum solvation methods, ${ }^{31}$ which were recently reviewed. ${ }^{32}$ Among the different approaches, the cluster-continuum static approximation (CCSA) is based on the cluster expansion method of the solvation free energy. ${ }^{33}$ Using this approximation, the solvation free energy is calculated according to the equation below:

$\Delta G_{\text {solv }}(X, C C S A) \cong \Delta G_{\text {solv }}(X$, continuum $)+\Delta W(X(S v) n)$

The first term in the right side is the solvation free energy of the solute $X$ calculated by a continuum method. The second term is the potential of mean force for formation of the cluster in solution phase involving $\mathrm{n}$ solvent molecules (Sv), which is calculated as follows:

$\Delta W(X(S v) n)=\Delta E(X(S v) n)+\Delta G_{\text {solv }}(X(S v) n)-\Delta G_{\text {solv }}(X)-n \Delta G_{\text {solv }}(S v)$

The first term in the right side is the variation of electronic energy involved in cluster formation. The remain terms are the solvation free energy of the cluster, of the solute $X$ and of the solvent molecules Sv calculated by the continuum model (SMD in this work).

\section{Neutral medium: carbinolamine formation does not occur through direct nucleophilic attack}

The reaction investigated in this work has multiple pathways with many equilibria taking place simultaneously. In this part of the study, the term neutral medium means that these several acid-base equilibria are not being considered. A more complete discussion of this reaction system is done in the kinetics analysis section.

The reaction between methylamine (MS1) and acetaldehyde (MS2) involves the formation of carbinolamine (MS3). The theoretical $\Delta G$ for this step has a value of $-1.6 \mathrm{kcal} \mathrm{mol}^{-1}$. The experimental data on a similar system provide a value of $-1.3 \mathrm{kcal} \mathrm{mol}^{-1}$, which is in excellent agreement with our theoretical value. The transition state TS1 corresponds to a bimolecular process and seems to be a direct nucleophilic attack of nitrogen atom of MS1 to the carbon atom in the carbonyl group of MS2, with a simultaneous proton transfer from nitrogen to oxygen. The calculated free energy barrier $\left(\Delta G^{\ddagger}\right)$ is $26.4 \mathrm{kcal} \mathrm{mol}^{-1}$ in aqueous solution. Previous theoretical studies have not considered the solvent effect in the geometry optimizations. ${ }^{13,34}$ However, the electronic energies are in agreement. Our $\Delta \mathrm{E}_{\mathrm{el}}$ barrier (M06-2X) is $22.9 \mathrm{kcal} \mathrm{mol}^{-1}$ while Pliego et al. have reported a value of $26.7 \mathrm{kcal} \mathrm{mol}^{-1}$ using single point MP2 calculations on the gas phase Hartree-Fock geometries. ${ }^{34}$ The solvent effect is very important to stabilize this TS, because the gas phase $\Delta \mathrm{G}^{\ddagger}$ is high, 34.4 $\mathrm{kcal} \mathrm{mol}^{-1}$. Nevertheless, we have found that in aqueous solution TS1 does not connect methylamine and acetaldehyde reactants to MS3 (carbinolamine). Rather, connects the zwitterion intermediate MSZ with the carbinolamine intermediate MS3 (see Figure 1). This is a very different behavior from gas phase optimizations. Because the free energy barrier for this mechanism is high, it is not able to explain the fast equilibrium for carbinolamine formation.

\section{Zwitterion formation occurs via direct nucleophilic attack}

The formation of a zwitterion intermediate, called MSZ, corresponds to direct nucleophilic attack of methylamine to acetaldehyde. We were able to locate the zwitterion when the optimization was done in solution phase and the corresponding free energy is $9.0 \mathrm{kcal} \mathrm{mol}^{-1}$. This species has a shallow minimum on the aqueous solution potential of mean force surface and the free energy barrier of the transition state leading to zwitterion formation is $13.2 \mathrm{kcal} \mathrm{mol}^{-1}$. Thus, the calculations predict that formation of the zwitterion is a fast process in aqueous solution. 


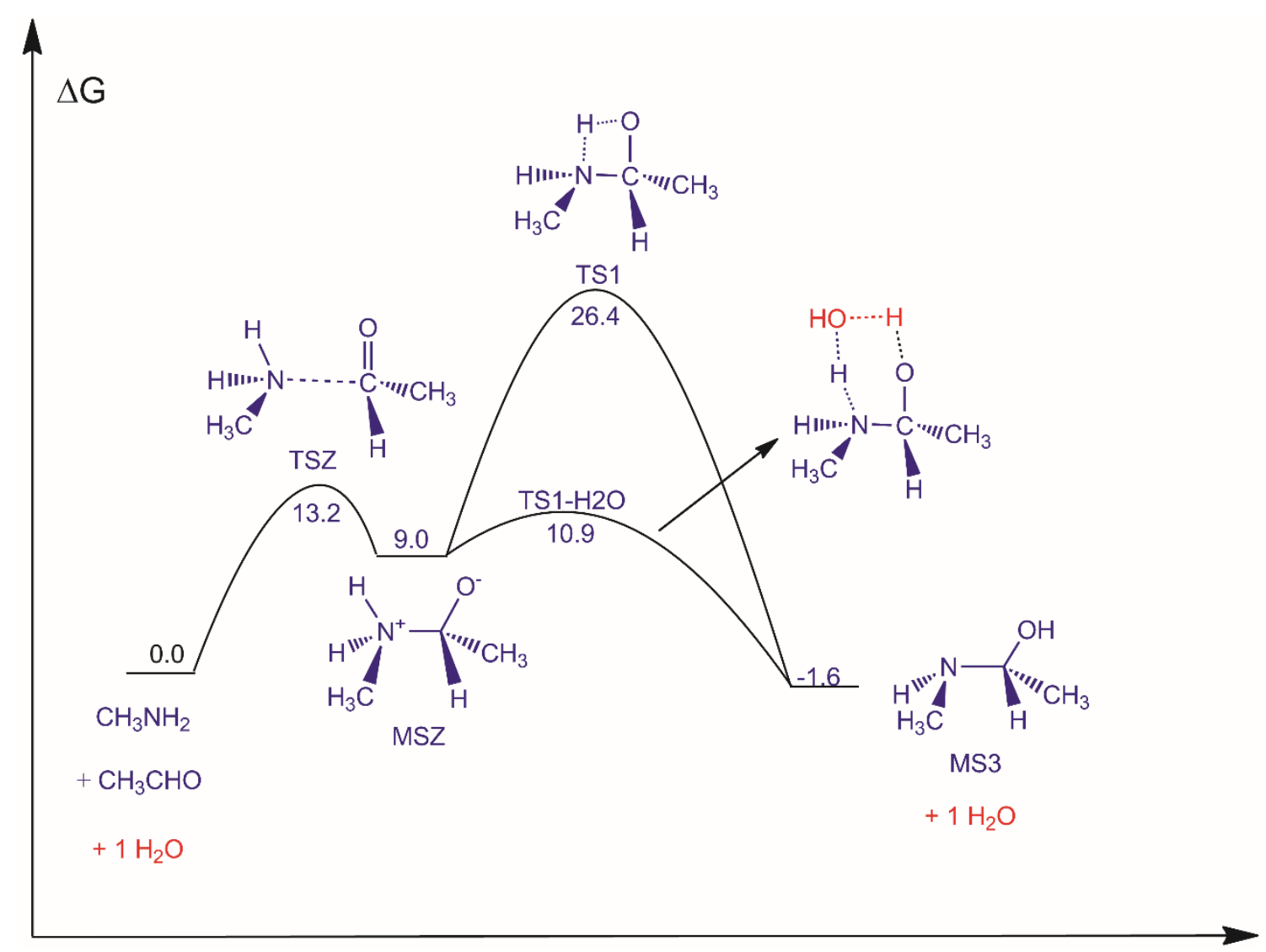

Figure 1. Free energy profile for carbinolamine formation in neutral medium via bimolecular process and with 1 water molecule as catalyst. Units in $\mathrm{kcal} \mathrm{mol}^{-1}$, standard state of $1 \mathrm{~mol} \mathrm{~L}^{-1}$ for all species but water, whose standard state is pure liquid.

\section{Zwitterion to carbinolamine isomerization via water-catalyzed proton shuttle mechanism}

The decomposition of the zwitterion can take place through a water-catalyzed proton shuttle mechanism. We have found that one or two water molecules can efficiently catalyze this process. In the case of one water molecule catalysis, the transformation of the zwitterion to the carbinolamine MS3 takes place in a single step via TS1-H2O. The water molecule takes the proton from the nitrogen of the zwitterion and donate a proton to the oxygen of the former carbonyl group. The free energy of this transient structure is calculated to be 10.9 $\mathrm{kcal} \mathrm{mol}^{-1}$, only $1.9 \mathrm{kcal} \mathrm{mol}^{-1}$ above of the zwitterion (Figure 1 ). Hence, the process takes place quickly. 


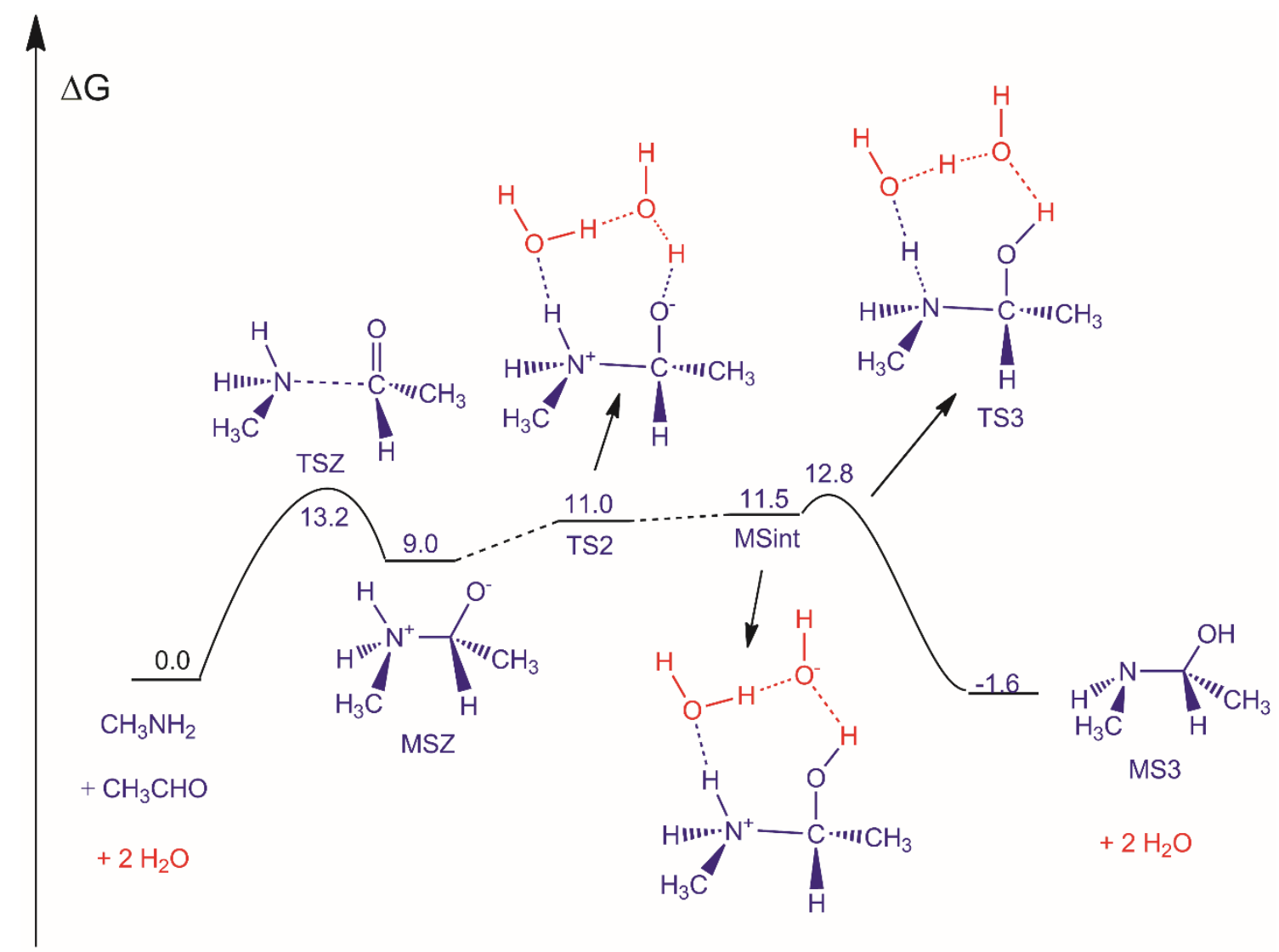

Figure 2. Free energy profile for carbinolamine formation in neutral medium with 2 water molecules acting as catalyst. Units in $\mathrm{kcal} \mathrm{mol}^{-1}$, standard state of $1 \mathrm{~mol} \mathrm{~L}^{-1}$ for all species but water, whose standard state is pure liquid.

The other pathway involves two water molecules catalyzing the proton transfer (Figure 2). The transition state TS2 shows a structure with substantial proton transfer from water to carbonyl, with a free energy of $11.0 \mathrm{kcal}$ $\mathrm{mol}^{-1}$. This leads to an even shallower minima structure (MSint) with a free energy of $11.5 \mathrm{kcal} \mathrm{mol}^{-1}$. Thus, the value of $\Delta \mathrm{G}$ for MSint is higher than TS2, although its $\Delta \mathrm{W}$ is $-13.4 \mathrm{kcal} \mathrm{mol}^{-1}$, below of the $\Delta \mathrm{W}$ of TS2, $-13.0 \mathrm{kcal}$ $\mathrm{mol}^{-1}$. Essentially, this short live intermediate has an ion-pair structure because it is possible to see a hydroxide ion like-structure separated by one water molecule of the $-\mathrm{N}_{(}\left(\mathrm{CH}_{3}\right) \mathrm{H}_{2}{ }^{+}$portion of the protonated carbinolamine. In the next step in the reaction pathway, there is the TS3 structure with a free energy of 12.8 $\mathrm{kcal} \mathrm{mol}^{-1}$. In this case, we can observe the simultaneous two proton transfer from the nitrogen to the water and from this species to the transient hydroxide ion, forming the carbinolamine intermediate. Overall, the free energy barrier for carbinolamine formation via the zwitterion is only $13.2 \mathrm{kcal} \mathrm{mol}^{-1}$, producing a fast kinetics (see Figures 1 and 2). This barrier is compatible with experimental data, because the experimental carbinolamine decomposition step (methylamine + isobutyraldehyde), considered the slowest step, has an experimentally reported $\Delta \mathrm{G}^{\ddagger}$ of $16.4 \mathrm{kcal} \mathrm{mol}^{-1}$. 
Table 1. Reaction and activation thermodynamic properties for the carbinolamine formation ${ }^{a}$

\begin{tabular}{|c|c|c|c|c|c|c|}
\hline Entry & process & $W^{b}$ & $M 06-2 X^{c}$ & $\Delta G n^{d}$ & $\Delta \Delta \mathrm{G}_{\text {solv }}{ }^{\mathrm{e}}$ & $\Delta \mathrm{G}_{\text {sol }}{ }^{\mathrm{f}}$ \\
\hline 1 & $\mathrm{MS} 1+\mathrm{MS} 2 \rightarrow \mathrm{MSZ}$ & -1.65 & 16.09 & 14.18 & -21.27 & 9.01 \\
\hline 2 & $\mathrm{MS} 1+\mathrm{MS} 2 \rightarrow \mathrm{MS} 3$ & -9.77 & -15.67 & 13.47 & 0.62 & -1.58 \\
\hline 3 & $\mathrm{MS} 1+\mathrm{MS} 2 \rightarrow \mathrm{TSZ}$ & 2.57 & 4.74 & 11.31 & -2.87 & 13.18 \\
\hline 4 & $\mathrm{MS} 1+\mathrm{MS} 2 \rightarrow \mathrm{TS} 1$ & 18.81 & 22.92 & 11.46 & -7.98 & 26.40 \\
\hline 5 & $\mathrm{MS} 1+\mathrm{MS} 2+\mathrm{H}_{2} \mathrm{O} \rightarrow \mathrm{TS} 1-\mathrm{H}_{2} \mathrm{O}$ & -4.99 & -0.17 & 22.04 & -8.57 & $\begin{array}{c}13.29 \\
(10.91)^{\mathrm{g}}\end{array}$ \\
\hline 6 & $\mathrm{MS} 1+\mathrm{MS} 2+2 * \mathrm{H}_{2} \mathrm{O} \rightarrow \mathrm{MSint}$ & -13.44 & -13.65 & 32.64 & -2.72 & $\begin{array}{c}16.27 \\
(11.51)^{\mathrm{g}}\end{array}$ \\
\hline 7 & $\mathrm{MS} 1+\mathrm{MS} 2+2^{*} \mathrm{H}_{2} \mathrm{O} \rightarrow \mathrm{TS} 2$ & -12.99 & -14.40 & 31.56 & -1.36 & $\begin{array}{c}15.80 \\
(11.04)^{\mathrm{g}}\end{array}$ \\
\hline 8 & $\mathrm{MS} 1+\mathrm{MS} 2+2 * \mathrm{H}_{2} \mathrm{O} \rightarrow \mathrm{TS} 3$ & -11.41 & -14.22 & 31.87 & -0.06 & $\begin{array}{c}17.60 \\
(12.84)^{\mathrm{g}}\end{array}$ \\
\hline
\end{tabular}

a Units in $\mathrm{kcal} \mathrm{mol}^{-1}$. Standard state of $1 \mathrm{~mol} \mathrm{~L}^{-1}$ for all the species. Values in parenthesis correspond to liquid water standard state. ${ }^{b}$ Potential of mean force, obtained at SMD/X3LYP/ma-def2-SVP level. c Electronic energy, using ma-def2TZVPP basis set. ${ }^{d}$ Translational, rotational and vibrational contributions to the free energy. e Solvent effect (water) obtained at SMD/X3LYP/ma-def2-SVP level of theory. ${ }^{f}$ Solution phase free energy. ${ }^{\mathrm{g}}$ Standard state of pure liquid for water.

\section{Dehydration of the carbinolamine for formation of the iminium ion}

The carbinolamine decomposition step by the neutral mechanism should lead to formation of (E)- and (Z)aldimines and a water molecule. In a study by Hall e Smith ${ }^{13}$ with formaldehyde and methylamine as substrates, the authors have located gas phase transition states leading to direct water elimination for imine formation or water elimination catalyzed by one or two water molecules. In the present work, we have not found a saddle point leading to water elimination with geometry optimizations in aqueous solution with the SMD model. Rather, we have found that the process involves elimination of the hydroxide ion, leading to the formation of the iminium ion. In addition, this step has an asymptotic barrier without an usual transition state. To prove this claim, we have done intrinsic reaction coordinate (IRC) calculations from the iminium and hydroxide pair of ions. The IRC calculations presented in Figure 3 point out that hydroxide ion addition to iminium ion in aqueous solution is a barrierless process. As a consequence, this addition reaction is a diffusioncontrolled process with a free energy barrier around $5 \mathrm{kcal} \mathrm{mol}^{-1}$. Such data can be used to estimate the free energy barrier for carbinolamine decomposition. However, first we need to evaluate the free energy for formation of the iminium and hydroxide ions. We have use three procedures described below (see Tables 2 and 3). 


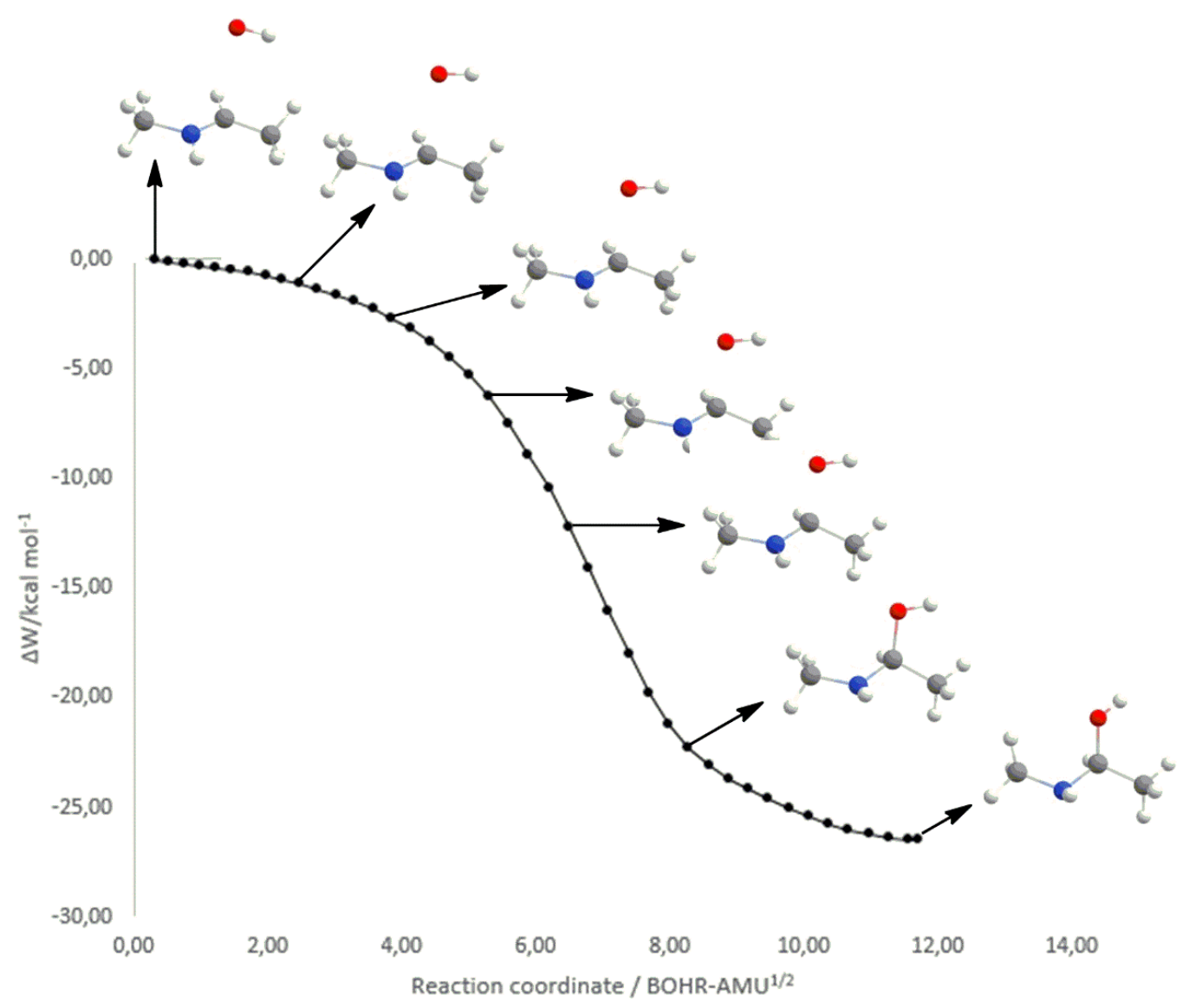

Figure 3. IRC calculations for carbinolamine formation from iminium and hydroxide ion at SMD/X3LYP/def2SVP level of theory.

The first procedure is the direct calculation of the reaction:

$\mathrm{MS} 3 \rightarrow \mathrm{CH}_{3} \mathrm{CH}=\mathrm{NHCH}_{3}{ }^{+}+\mathrm{OH}^{-}$

The solvation free energy for each species was obtained by the SMD model, which is not a recommended method for processes leading to the formation of charged species. According to the values presented in entries 1 and 2 of Table 3, the process for formation of these ionic species would involve a $\Delta G_{\text {sol }}$ of $20.6 \mathrm{kcal}$ $\mathrm{mol}^{-1}$ for $\mathrm{MS}_{4} \mathrm{H}^{+}$and $\mathrm{OH}^{-}$and $19.3 \mathrm{kcal} \mathrm{mol}^{-1}$ for $\mathrm{MS}^{\circ} \mathrm{H}^{+}$and $\mathrm{OH}^{-}$.

The second method is the use of a hybrid discrete-continuum approach. We have used the cluster-continuum static approximation (CCSA) recently proposed. ${ }^{33}$ This method was discussed in the methodology section. We have solvated the MS3 by four solvent molecules and added the continuum SMD. In the product, these four water molecules were also used, with three water solvating the hydroxide ion and one water molecule solvating the iminium ion ( $\mathrm{MS}_{4} \mathrm{H}^{+}$or $\mathrm{MS}^{2} \mathrm{H}^{+}$, see Figure 4). Table 3 presents the values for solvation free energy obtained by the CCSA, as well as solution free energy values. As we can see, the CCSA provide substantial more stabilization for the $\mathrm{MS}_{4} \mathrm{H}^{+}$and $\mathrm{MS}^{+} \mathrm{H}^{+}$iminium ions and the $\Delta \mathrm{G}$ become 11.3 and $10.0 \mathrm{kcal}$ $\mathrm{mol}^{-1}$, respectively (Table 3, entries 13 and 14 ). 


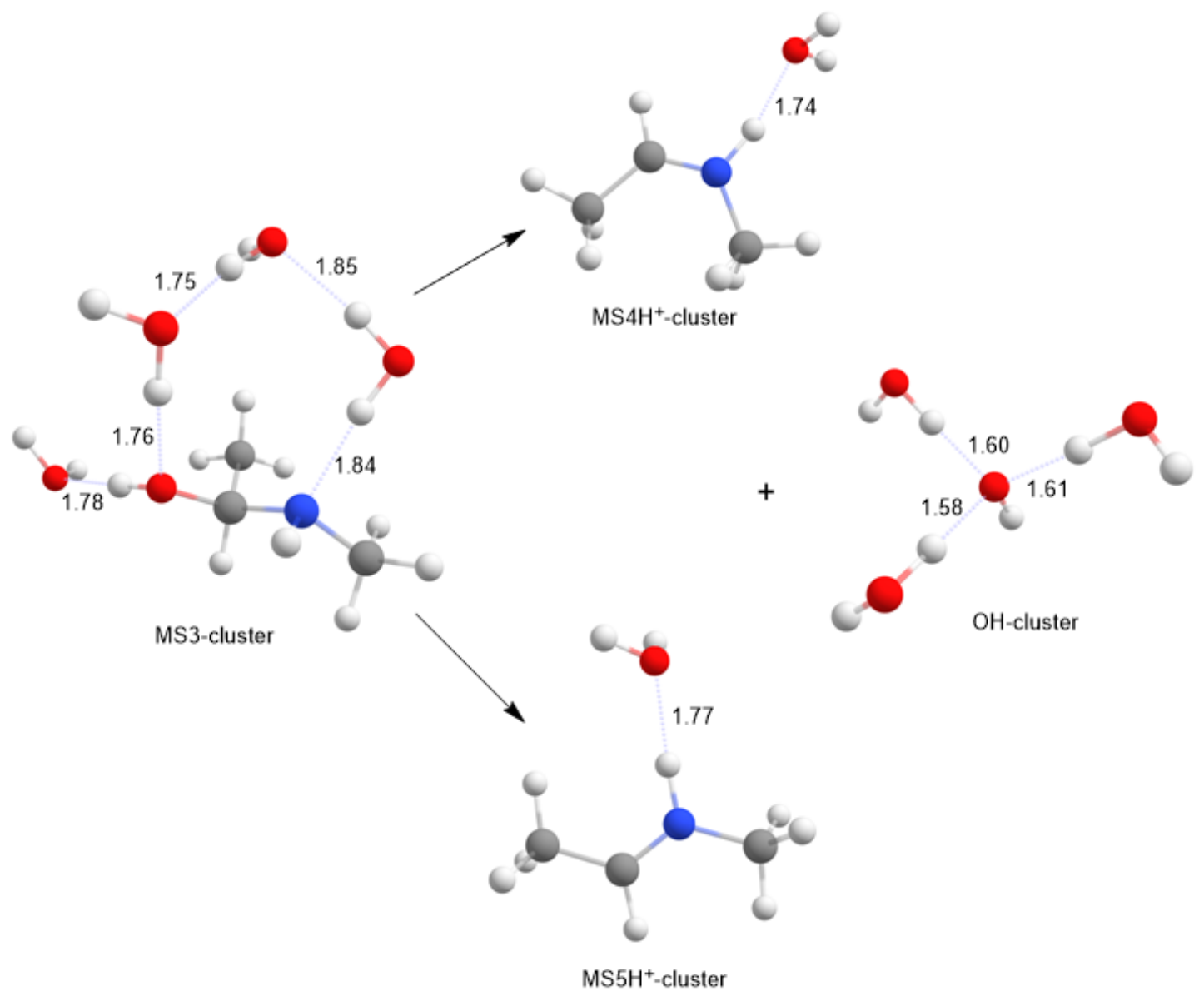

Figure 4. Species involved in the calculation of solvation free energy by CCSA.

The third method involve the use of a combination of theoretical and experimental data. Thus, consider the combinations of entries 3, 4 and 5 in the Table 3 to obtain entry 6 . Entry 3 is a theoretical data obtained using the SMD model. However, because similar charged species are on the both side of the equation, the error of the SMD model is substantially cancelled. On the other hand, the $\Delta G^{\prime}$ 's of the entries 4 and 5 are related to the experimental $\mathrm{pK}_{\mathrm{a}}$ of pyiridine and the self-ionization of water. The free energy involved in the formation Ziminium and $\mathrm{OH}^{-}$is on the entry 6 and corresponds to the sum of entries 3 to 5 . Similarly, we used the combination of entries 7, 4 and 5 to obtain the free energy involved in the formation of E-iminium and $\mathrm{OH}^{-}$ (entry 8). The values are 5.7 and $4.4 \mathrm{kcal} \mathrm{mol}^{-1}$, respectively (entries 6 and 8). We consider this third method as the most reliable. Further, we can notice that the hybrid CCSA provides substantial improvement on the SMD pure continuum solvation method. 


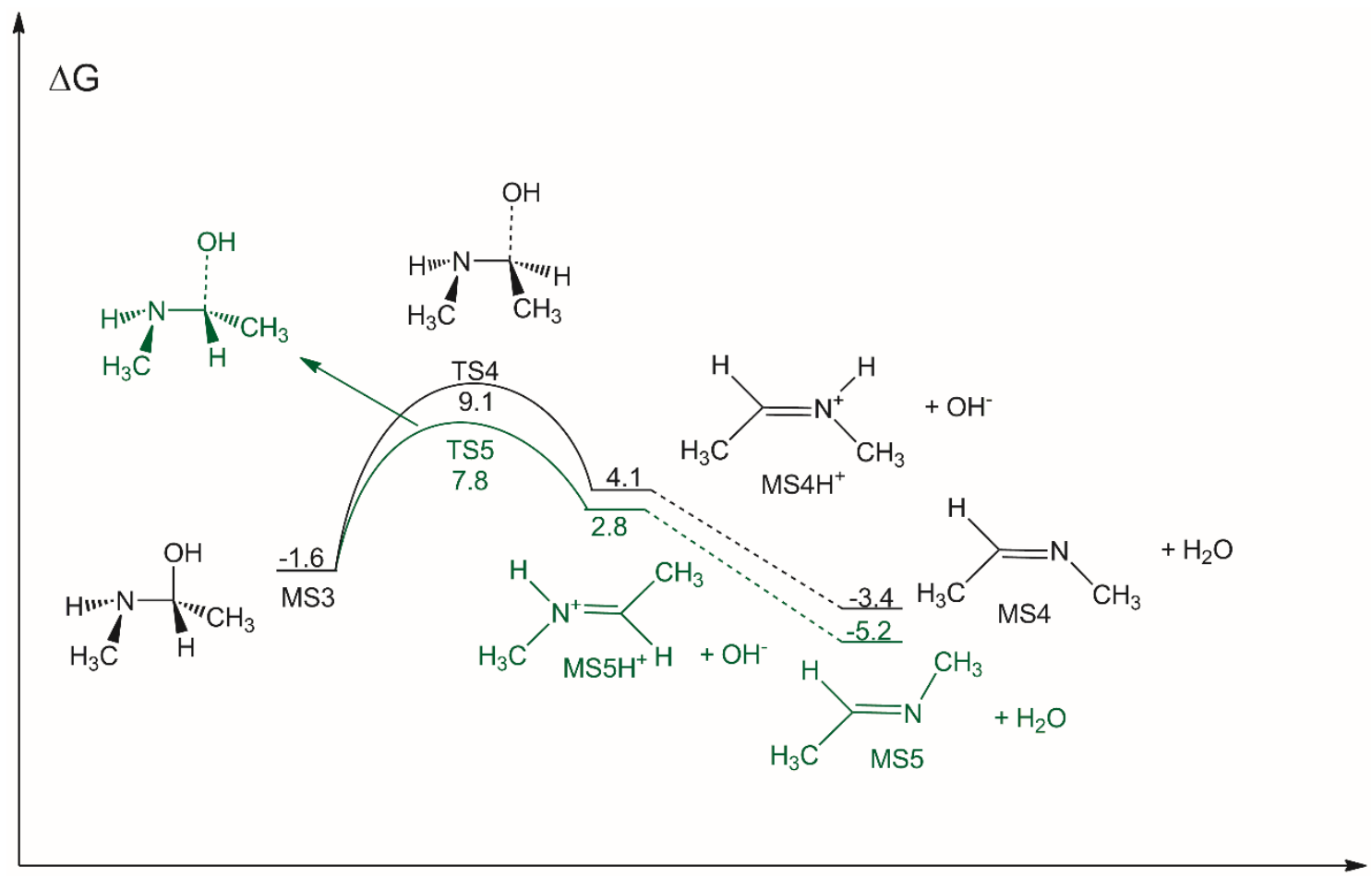

Figure 5. Free energy profile for carbinolamine decomposition in neutral medium. Units in kcal mol-1, $\mathrm{standard}^{-1}$ state of $1 \mathrm{~mol} \mathrm{~L}^{-1}$ for all species but water, whose standard state is pure liquid.

As a final step, the formed ionic species undergo rapid proton exchange with the solvent, leading to the formation of MS4 and $\mathrm{H}_{2} \mathrm{O}$ with a free energy in solution of $-3.4 \mathrm{kcal} \mathrm{mol}^{-1}$ and formation of MS5 and $\mathrm{H}_{2} \mathrm{O}$ with a free energy in solution of $-5.2 \mathrm{kcal} \mathrm{mol}^{-1}$. These values are relative to the initial reactants. Figure 5 presents free energy profile of the carbinolamine decomposition reaction. We can observe that the lowest $\Delta \mathrm{G}^{\ddagger}$ barrier is $7.8-(-1.6)=9.4 \mathrm{kcal} \mathrm{mol}^{-1}$, via TS5. In the experiments on methylamine addition to isobutyraldehyde, this barrier was determined as $16.4 \mathrm{kcal} \mathrm{mol}^{-1}$, a deviation of $7 \mathrm{kcal} \mathrm{mol}^{-1}$. The reasons for this difference can be the substantial solvent effect present in this step (formation of a pair of ions), which is difficult for modeling, and the fact that we are studying the acetaldehyde rather than isobutyraldehyde.

Based on the complete theoretical free energy profile, the formation of the zwitterion is the slowest step, with $\Delta \mathrm{G}^{\ddagger}$ barrier of $13.2 \mathrm{kcal} \mathrm{mol}^{-1}$. This conclusion, based only on the free energy profile, needs be better

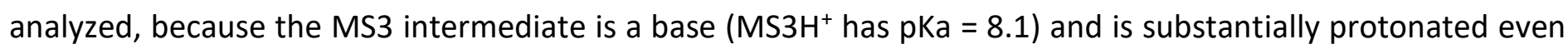
in $\mathrm{pH}$ close to 7, leading to low concentration of MS3 and decreasing the kinetics. This point will be discussed ahead.

Table 2. Theoretical determination of pKa and free energy of protonation ${ }^{a}$

\begin{tabular}{|c|c|c|c|c|c|}
\hline Species & $M 06-2 X^{b}$ & $\Delta \mathrm{Gn}$ & $\Delta \Delta \mathrm{G}_{\text {solv }}{ }^{\mathrm{c}}$ & $\Delta \mathrm{G}_{\mathrm{sol}}^{\mathrm{d}}$ & pKa \\
\hline 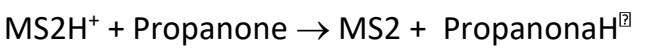 & -10.40 & -0.54 & 7.11 & -3.83 & -5.87 \\
\hline 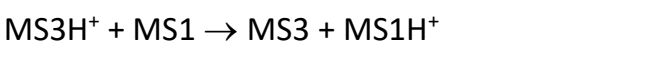 & 6.24 & -0.62 & -9.07 & -3.45 & 8.11 \\
\hline 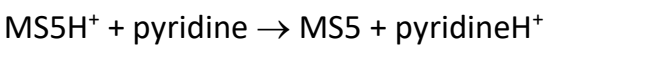 & 1.13 & 0.46 & 2.42 & 4.01 & 8.16 \\
\hline Processes & pKa & $\Delta \mathrm{G}_{\mathrm{sol}}$ & & & \\
\hline $\mathrm{MS}_{2} \mathrm{H}^{+} \rightarrow \mathrm{MS} 2+\mathrm{H}^{+}$ & -5.87 & -8.01 & & & \\
\hline
\end{tabular}




\begin{tabular}{lll}
\hline${\mathrm{MS} 3 \mathrm{H}^{+} \rightarrow \mathrm{MS} 3+\mathrm{H}^{+}}$ & 8.11 & 11.07 \\
PyridineH & $5.22^{35}$ & 7.13 \\
$\mathrm{MS} \mathrm{P} \mathrm{H}^{+} \rightarrow \mathrm{MS} 1+\mathrm{H}^{\natural}$ & $10.64^{35}$ & 14.53 \\
PropanoneH & $-3.06^{36}$ & -4.18 \\
$\mathrm{H}_{2} \mathrm{O} \rightarrow \mathrm{OH}^{+}+\mathrm{H}^{+}$ & $15.74^{36}$ & 21.49 \\
$\mathrm{MS}^{+} \mathrm{H}^{+} \rightarrow \mathrm{MS} 5+\mathrm{H}^{+}$ & 8.16 & 11.14 \\
\hline
\end{tabular}

a Units in $\mathrm{kcal} \mathrm{mol}^{-1}$. Standard state of $1 \mathrm{~mol} \mathrm{~L}^{-1}$ for all the processes. Geometry optimizations and frequencies obtained at SMD/X3LYP/ma-def2-SVP level. b Using madef2-TZVPP basis set. ${ }^{c}$ Solvent effect obtained at SMD/X3LYP/ma-def2-SVP level of theory. ${ }^{\mathrm{d}}$ Solution phase free energy.

Table 3. Reaction and activation thermodynamic properties for imine mechanism ${ }^{a}$

\begin{tabular}{|c|c|c|c|c|c|c|}
\hline Entry & $\begin{array}{l}\text { process } \\
\text { Iminium Formation } \\
\text { - Direct method }\end{array}$ & $W^{b}$ & $M 06-2 X^{c}$ & $\Delta G n^{d}$ & $\Delta \Delta \mathrm{G}_{\text {solv }}{ }^{\mathrm{e}}$ & $\Delta \mathrm{G}_{\mathrm{sol}}{ }^{\mathrm{f}}$ \\
\hline 1 & $\begin{array}{l}\mathrm{MS} 3 \rightarrow \mathrm{MS} \mathrm{H}^{+}+ \\
\mathrm{OH}^{-}\end{array}$ & 25.46 & 181.48 & -11.66 & -149.21 & 20.62 \\
\hline 2 & $\begin{array}{l}\mathrm{MS3} \rightarrow{\mathrm{MS} 5 \mathrm{H}^{+}+} \mathrm{OH}^{-} \\
\end{array}$ & 24.02 & 179.92 & -11.42 & -149.16 & 19.34 \\
\hline & $\begin{array}{l}\text { Iminium Formation } \\
\text { - Indirect method } \\
\text { process }\end{array}$ & $w^{b}$ & $M 06-2 X^{c}$ & $\Delta G n^{d}$ & $\Delta \Delta \mathrm{G}_{\text {solv }}{ }^{\mathrm{e}}$ & $\Delta \mathrm{G}_{\text {sol }}{ }^{\mathrm{f}}$ \\
\hline 3 & $\begin{array}{l}\mathrm{MS} 3+\text { pyridine }^{+} \\
\rightarrow \mathrm{MS}_{4} \mathrm{H}^{+}+\mathrm{H}_{2} \mathrm{O}+ \\
\text { pyridine }\end{array}$ & 2.72 & 12.49 & -13.60 & -7.58 & -8.69 \\
\hline 4 & $\begin{array}{l}\text { Pyridine }+\mathrm{H}^{+} \rightarrow \\
\text { Pyridine }^{+}\end{array}$ & & & & & -7.13 \\
\hline 5 & $\mathrm{H}_{2} \mathrm{O} \rightarrow \mathrm{OH}^{-}+\mathrm{H}^{+}$ & & & & & 21.49 \\
\hline 6 & $\begin{array}{l}\mathrm{MS} 3 \rightarrow \mathrm{MS} \mathrm{H}^{+}+ \\
\mathrm{OH}^{-}\end{array}$ & & & & & 5.67 \\
\hline 7 & 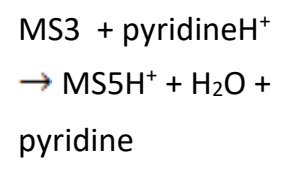 & 1.28 & 10.92 & -13.36 & -7.53 & -9.97 \\
\hline 8 & $\begin{array}{l}\mathrm{MS3} \rightarrow{\mathrm{MS} 5 \mathrm{H}^{+}+}^{\mathrm{OH}^{-}}\end{array}$ & & & & & 4.39 \\
\hline & $\begin{array}{l}\text { CCSA } \\
\text { process }\end{array}$ & $\Delta \mathrm{E}\left(\mathrm{S}\left(\mathrm{S}_{\mathrm{v}}\right)_{\mathrm{n}}\right)$ & $\Delta \mathrm{G}_{\text {solv }}(\mathrm{SMD})$ & $\Delta \Delta \mathrm{G}_{\text {solv }}$ & $\Delta \mathrm{W}$ & $\Delta \mathrm{G}_{\text {solv }}(\mathrm{CCSA})$ \\
\hline 9 & $\begin{array}{l}\mathrm{MS} 3+4 \mathrm{H}_{2} \mathrm{O} \rightarrow \\
\text { MS3-cluster }\end{array}$ & -23.53 & -8.26 & 10.91 & -12.62 & -20.88 \\
\hline 10 & $\begin{array}{l}\mathrm{MS} 4 \mathrm{H}^{+}+\mathrm{H}_{2} \mathrm{O} \rightarrow \\
\mathrm{MS} 4 \mathrm{H}^{+} \text {-cluster }\end{array}$ & -14.81 & -61.55 & 12.10 & -2.72 & -64.27 \\
\hline
\end{tabular}




\begin{tabular}{|c|c|c|c|c|c|c|}
\hline \multirow[t]{2}{*}{11} & $\mathrm{MS} 5 \mathrm{H}^{+}+\mathrm{H}_{2} \mathrm{O} \rightarrow$ & -14.10 & -61.51 & 11.38 & -2.71 & -64.22 \\
\hline & MS5H $\mathrm{H}^{+}$-cluster & & & & & \\
\hline \multirow[t]{3}{*}{12} & $\begin{array}{l}\mathrm{OH}^{-}+3 \mathrm{H}_{2} \mathrm{O} \rightarrow \mathrm{OH}- \\
\text { cluster }\end{array}$ & -67.79 & -95.91 & 48.56 & 19.22 & -115.13 \\
\hline & $\begin{array}{l}\text { Solution free energy } \\
\text { by CCSA }\end{array}$ & & & & & \\
\hline & process & $W^{b}$ & $M 06-2 X^{c}$ & $\Delta G n^{d}$ & $\Delta \Delta \mathrm{G}_{\text {solv }}(\mathrm{CCSA})$ & $\Delta \mathrm{G}_{\text {sol }}{ }^{\mathrm{f}}$ \\
\hline \multirow[t]{2}{*}{13} & $\mathrm{MS} 3 \rightarrow \mathrm{MS} \mathrm{H}^{+}+$ & 25.46 & 181.48 & -11.66 & -158.52 & 11.30 \\
\hline & $\mathrm{OH}^{-}$ & & & & & \\
\hline \multirow[t]{4}{*}{14} & 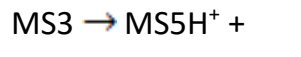 & 24.02 & 179.92 & -11.42 & -158.47 & 10.02 \\
\hline & $\mathrm{OH}^{-}$ & & & & & \\
\hline & Imine Formation & & & & & \\
\hline & process & $w^{b}$ & $M 06-2 X^{c}$ & $\Delta G n^{d}$ & $\Delta \Delta \mathrm{G}_{\text {solv }} \mathrm{e}^{\mathrm{e}}$ & $\Delta \mathrm{G}_{\text {sol }}{ }^{\mathrm{f}}$ \\
\hline \multirow[t]{2}{*}{15} & $\mathrm{MS} 1+\mathrm{MS} 2 \rightarrow \mathrm{MS} 4$ & -2.62 & -0.07 & 0.10 & -5.81 & -5.78 \\
\hline & $+\mathrm{H}_{2} \mathrm{O}$ & & & & & $(-3.40)^{\mathrm{g}}$ \\
\hline \multirow[t]{2}{*}{16} & MS1 + MS2 $\rightarrow$ MS5 & -5.56 & -3.62 & 0.57 & -4.48 & -7.54 \\
\hline & $+\mathrm{H}_{2} \mathrm{O}$ & & & & & $(-5.16)^{\mathrm{g}}$ \\
\hline
\end{tabular}

a Units in $\mathrm{kcal} \mathrm{mol}^{-1}$. Standard state of $1 \mathrm{~mol} \mathrm{~L}^{-1}$ for all the species. Values in parenthesis correspond to pure methanol standard state. ${ }^{b}$ Potential of mean force, obtained at SMD/X3LYP/ma-def2-SVP level. ' Electronic energy, using ma-def2-TZVPP basis set. ${ }^{d}$ Translational, rotational and vibrational contributions to the free energy. ${ }^{e}$ Solvent effect (methanol) obtained at SMD/X3LYP/ma-def2-SVP level of theory. ${ }^{f}$ Solution phase free energy. ${ }^{\mathrm{g}}$ Standard state of pure liquid for water.

\section{Acid medium: reaction between protonated methylamine and acetaldehyde}

In low $\mathrm{pH}$, the methylamine is protonated and the reaction proceeds by proton transfer from protonated methylamine to the oxygen of the acetaldehyde as the first step. This process is very unfavorable, with a free energy of $22.5 \mathrm{kcal} \mathrm{mol}^{-1}$ (Figure 6 and Table 4). In the next step, a diffusion-controlled methylamine addition to protonated acetaldehyde takes place, which is confirmed by IRC calculations (Figure 7). This step leads to the formation of protonated carbinolamine $\left(\mathrm{MS} \mathrm{H}^{+}\right)$. Because the formation of carbinolamine via neutral species has much lower free energy barrier, even in acid medium the carbinolamine formation takes place via mechanism of Figure 1. 


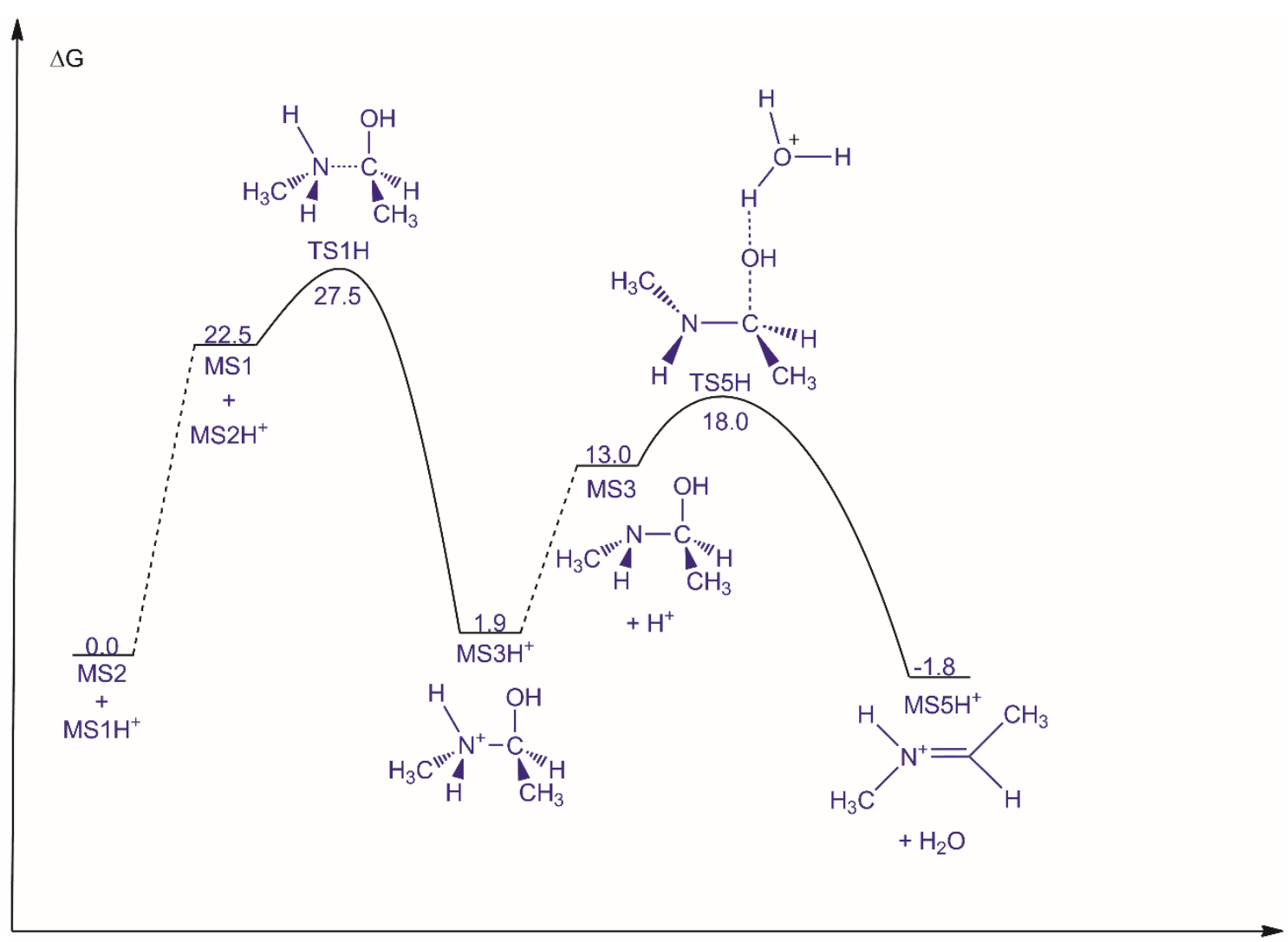

Figure 6. Free energy profile for carbinolamine formation and decomposition in acid medium (formation of Eisomer). Units in $\mathrm{kcal} \mathrm{mol}^{-1}$, standard state of $1 \mathrm{~mol} \mathrm{~L}^{-1}$ for all species but water, whose standard state is pure liquid.

The decomposition of $\mathrm{MS} \mathrm{H}^{+}$takes place by proton transfer to the medium, forming $\mathrm{H}_{3} \mathrm{O}^{+}$and carbinolamine (MS3). The next step is the elimination of $\mathrm{OH}^{-}$from MS3 catalyzed by $\mathrm{H}_{3} \mathrm{O}^{+}$. We have observed that there is not an activation barrier $\left(\Delta \mathrm{W}^{\ddagger}\right)$ for this step, which is a diffusion-controlled process with an estimated overall free energy of $18.0 \mathrm{kcal} \mathrm{mol}^{-1}$ (Figure 6, formation of E-isomer). Thus, the free energy profile points out a slower process in very acidic medium and the first step $\left(\mathrm{MS} \mathrm{H}^{+}\right.$formation) is the rate-determining one. It is also worth to observe that the final imine product (in fact, the iminium $\mathrm{MS}_{5} \mathrm{H}^{+}$) is less stable compared to the initial reactants in acid medium than in higher $\mathrm{pH}$. 
Table 4. Reaction and activation thermodynamic properties for iminium mechanism ${ }^{\text {a }}$

\begin{tabular}{|c|c|c|c|c|c|c|}
\hline Entry & process & $W^{b}$ & $M 06-2 X^{c}$ & $\Delta G n^{d}$ & $\Delta \Delta \mathrm{G}_{\text {solv }} \mathrm{e}^{\mathrm{e}}$ & $\Delta G_{\text {sol }}{ }^{f}$ \\
\hline 1 & $\mathrm{MS}_{1} \mathrm{H}^{+}+\mathrm{MS} 2 \rightarrow \mathrm{MS}_{2} \mathrm{H}^{+}+\mathrm{MS} 1$ & & & & & $22.54^{\mathrm{g}}$ \\
\hline 2 & $\mathrm{MS} 1+\mathrm{MS} 2 \rightarrow \mathrm{MS} 3$ & -9.77 & -15.67 & 13.47 & 0.62 & -1.58 \\
\hline 3 & 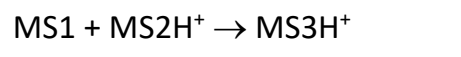 & & & & & $-20.66^{h}$ \\
\hline 4 & $\begin{array}{l}\mathrm{MS}+\text { pyridine }{ }^{+} \rightarrow \mathrm{MS} \mathrm{H}^{+}+ \\
\mathrm{H}_{2} \mathrm{O}+\text { pyridine }\end{array}$ & 2.72 & 12.49 & -13.60 & -7.58 & -8.69 \\
\hline 5 & $\mathrm{MS} \mathrm{H}^{+} \rightarrow \mathrm{MS} \mathrm{H}^{+}+\mathrm{H}_{2} \mathrm{O}$ & & & & & $\begin{array}{l}-4.75^{i} \\
(-2.37)^{j}\end{array}$ \\
\hline 6 & $\begin{array}{l}\mathrm{MS}_{3}+\text { pyridine } \mathrm{H}^{+} \rightarrow{\mathrm{MS} 5 \mathrm{H}^{+}+}^{\mathrm{H}_{2} \mathrm{O}+\text { pyridine }}\end{array}$ & 1.28 & 10.92 & -13.36 & -7.53 & -9.97 \\
\hline 7 & $\mathrm{MS}_{3} \mathrm{H}^{+} \rightarrow \mathrm{MS}_{5} \mathrm{H}^{+}+\mathrm{H}_{2} \mathrm{O}$ & & & & & $\begin{array}{l}-6.03^{k} \\
(-3.65)^{j}\end{array}$ \\
\hline
\end{tabular}

a Units in $\mathrm{kcal} \mathrm{mol}^{-1}$. Standard state of $1 \mathrm{~mol} \mathrm{~L}^{-1}$ for all the species. Values in parenthesis correspond to pure water standard state. ${ }^{b}$ Potential of mean force, obtained at SMD/X3LYP/ma-def2-SVP level. ' Electronic energy, using ma-def2TZVPP basis set. ${ }^{d}$ Translational, rotational and vibrational contributions to the free energy. e Solvent effect (water) obtained at SMD/X3LYP/ma-def2-SVP level of theory. ${ }^{f}$ Solution phase free energy. ${ }^{\mathrm{g}}$ Based on pKa of $\mathrm{MS} \mathrm{H}^{+}$and $\mathrm{MS}_{2} \mathrm{H}^{+} .{ }^{\mathrm{h}}$ Based on Entry 2 and pKa's of $\mathrm{MS} \mathrm{H}^{+}$and $\mathrm{MS} 3 \mathrm{H}^{+}$. ' Based on Entry 4 and pKa's of $\mathrm{MS}^{\mathrm{i}} \mathrm{H}^{+}$ and pyridine $\mathrm{H}^{+}$. jStandard state of pure liquid for water. ${ }^{k}$ Based on Entry 6 and pKa's of $\mathrm{MS} \mathrm{H}^{+}$and pyridine $\mathrm{H}^{+}$.

\section{Reaction kinetics as a function of the $\mathrm{pH}$}

The free energy profile provides important information on the viability of the reaction and is possible to use this data to derive the kinetics law, as well as the reaction rate. However, a system with a pH-depending mechanism can have a very complex kinetics and more reliable theoretical description of a reaction process requires an analysis of the effect of the concentration of each species. Thus, we have done a stationary-state analysis of the kinetics of the reaction. The protonated carbinolamine is considered the stationary species because in acid and neutral $\mathrm{pH}$ the carbinolamine intermediate $\left(\mathrm{pK}_{\mathrm{a}}=8.1\right)$ is protonated in large extension. Further, deprotonation of MS3 for formation of an anionic intermediate only takes place in very basic medium $(\mathrm{pKa}=13.8)$. 


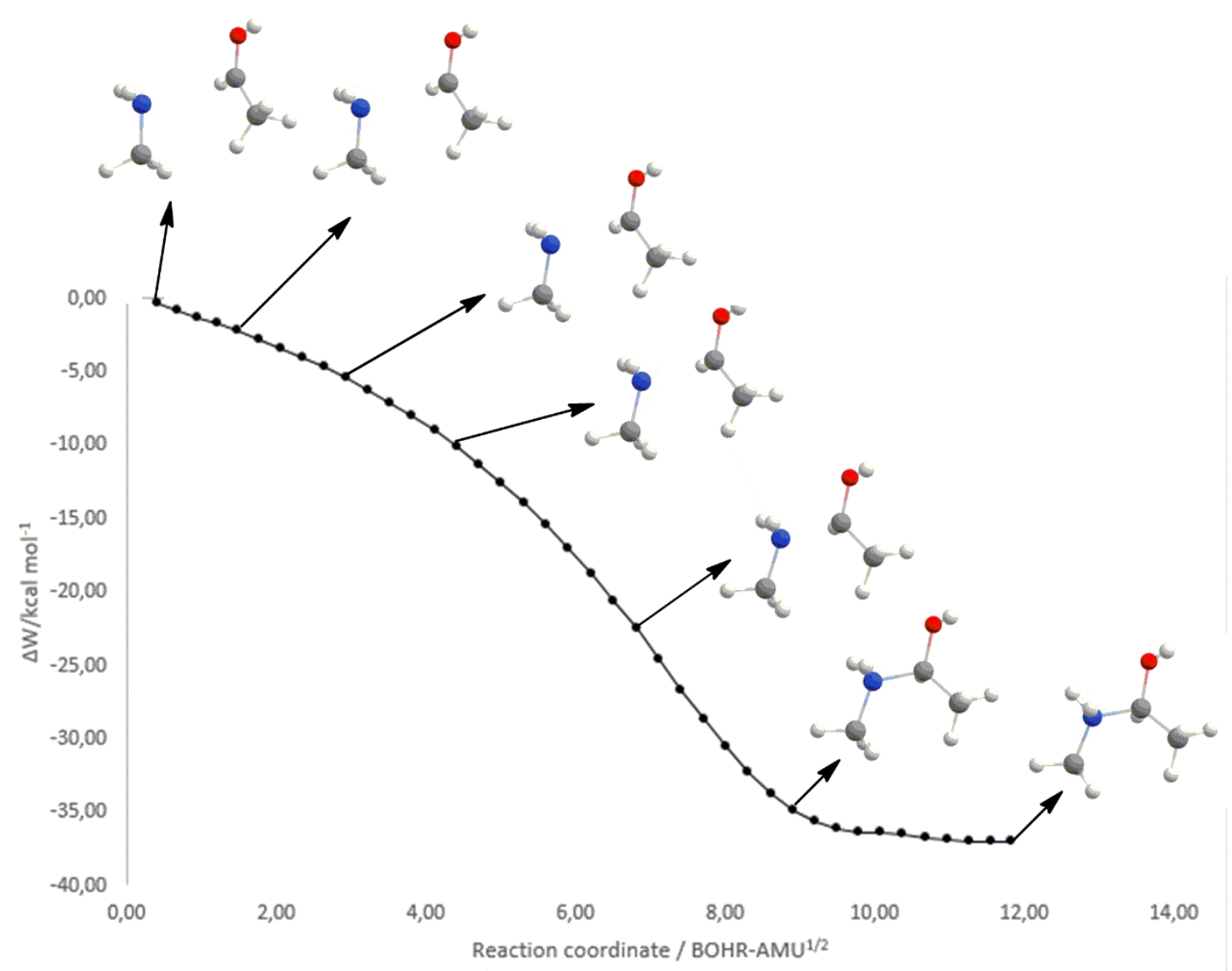

Figure 7. IRC calculations for methylamine addition to protonated acetaldehyde using the SMD/X3LYP/def2SVP level of theory.

The kinetics and equilibria involved in the present system is presented below, with rate constants calculated from transition state theory and the data taken from the free energy profile and Tables presented in this work:

$$
\begin{aligned}
& M S 1+M S 2 \rightleftharpoons M S 3 \quad k_{1}=1,3 \times 10^{3} L \cdot \mathrm{mol}^{-1} \mathrm{~s}^{-1} \\
& k_{-1}=8.8 \times 10^{1} s^{-1} \\
& M S 3 \rightarrow \mathrm{MS}^{2} \mathrm{H}^{+}+\mathrm{OH}^{-} \quad k_{2}=8.0 \times 10^{5} \mathrm{~s}^{-1} \\
& \mathrm{MS} 3+\mathrm{H}_{3} \mathrm{O}^{+} \rightarrow \mathrm{MS}^{2} \mathrm{H}^{+}+2 \mathrm{H}_{2} \mathrm{O} \quad k_{3}=1.3 \times 10^{9} \mathrm{~L} \mathrm{~mol}^{-1} \mathrm{~s}^{-1} \\
& M S 1 H^{+} \rightleftharpoons M S 1+H^{+} \quad K_{a 1}=2.3 \times 10^{-11} \\
& M S 3 H^{+} \rightleftharpoons M S 3+H^{+} \quad K_{a 3}=7.8 \times 10^{-9}
\end{aligned}
$$

Taking the $\mathrm{MS} \mathrm{H}^{+}$as the stationary species, we can write:

$\frac{d\left[M S 3 H^{+}\right]}{d t}=k_{1}[M S 1][M S 2]-k_{-1}[M S 3]-k_{2}[M S 3]-k_{3}[M S 3]\left[H^{+}\right]=0$

Observe that in the above equation, $\mathrm{MS3}$ and $\mathrm{MS} \mathrm{H}^{+}$species are assumed to have a very fast acid-base equilibrium. Further, $\mathrm{MS} \mathrm{H}^{+}$is the predominant species in acid and neutral $\mathrm{pH}$. Thus, $\mathrm{k}_{1}$ leads to formation of MS3, followed of fast protonation to form $\mathrm{MS} \mathrm{H}^{+}$and the pathways for decomposition of MS3 also leads to the same rate for decomposition of $\mathrm{MS}_{3} \mathrm{H}^{+}$. 
Analyzing the rate constants, we can notice that the reaction via $k_{-1}$ does no compete with $k_{2}$, because $k_{2}>>k_{-}$ 1. Thus, this term with $\mathrm{k}_{-1}$ can be eliminated and we can conclude (based on our theoretical data) that MS3 and $\mathrm{MS} 3 \mathrm{H}+$ reach a stationary concentration, not an equilibrium with the reactants. In addition, comparing $\mathrm{k}_{2}$ with $\mathrm{k}_{3}\left[\mathrm{H}^{+}\right]$, the decomposition of MS3 (and $\mathrm{MS} \mathrm{H}^{+}$) depend on the $\mathrm{pH}$. For $\mathrm{pH}<3.2$ the decomposition occurs mainly via TS5H and above of this $\mathrm{pH}$ the process occurs mainly via TS5. Based on the above equations, the concentration of MS3H+ can be written as:

$\left[M S 3 H^{+}\right]=\frac{\left(k_{1} K_{a 1} /\left[H^{+}\right]\right) \cdot\left[M S 1 H^{+}\right][M S 2]}{k_{3} K_{a 3}+\left(\left(k_{2}+k_{-1}\right) \cdot K_{a 3} /\left[H^{+}\right]\right)}$

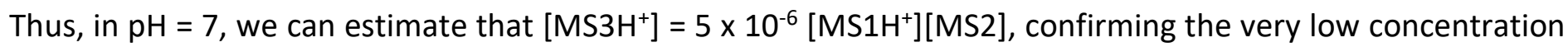
of this stationary species.

Based on the above analysis, the reaction rate for formation of the product is the same reaction rate for decomposition of the initial reactants (slow step) and is given by:

$\frac{d[\text { product }]}{d t}=\left(k_{1} K_{a 1} /\left[H^{+}\right]\right) \cdot\left[M S 1 H^{+}\right][M S 2]$

Equation (11) point out that the reaction is first order in both amine and aldehyde and the reaction rate increases with the $\mathrm{pH}$ until it reaches 10.6, the pKa of methylamine. In the $\mathrm{pH}=7$ and considering the concentration of the initial reactants as $0.10 \mathrm{~mol} \mathrm{~L}^{-1}$, the reaction rate becomes $0.003 \mathrm{~mol} \mathrm{~L}^{-1} \mathrm{~s}^{-1}$, which leads to an effective $\Delta G^{\ddagger}=18.2 \mathrm{kcal} \mathrm{mol}^{-1}$, compatible with the fast experimental kinetics of this reaction.

\section{Conclusions}

A detailed analysis of the mechanism of imine formation in aqueous solution and variable $\mathrm{pH}$ points out that the reaction proceeds by direct attack of methylamine to acetaldehyde with formation of a zwitterion, followed by its decomposition to the carbinolamine intermediate via proton shuttle mechanism catalyzed by water. The calculations have determined a low free energy barrier of $13.2 \mathrm{kcal} \mathrm{mol}^{-1}$ for this step and indicated that this is the rate-determining one. In low $\mathrm{pH}$ the protonation of methylamine decreases the kinetics and the equilibrium for imine (iminium ion) formation. The decomposition of carbinolamine takes place by hydroxide ion elimination step with a low free energy barrier of $9.4 \mathrm{kcal} \mathrm{mol}^{-1}$. Protonation of the carbinolamine also decreases the kinetics of this step and no maximum in the $\mathrm{pH}$-rate profile $(\mathrm{pH}<10)$ is predicted. More detailed study of the carbinolamine decomposition step using more sophisticated solvation methods is worthwhile.

\section{Supplementary Material}

Coordinates of all the optimized species and the corresponding 3D structures.

\section{Acknowledgements}

The authors thank the Brazilian agencies FAPEMIG, CNPq and CAPES for financial support. 


\section{References}

1. Kobayashi, S.; Ishitani, H. Chem. Rev. 1999, 99, 1069. https://doi.org/10.1021/cr980414z

2. Vilaivan, T.; Bhanthumnavin, W.; Sritana-Anant, Y. Curr. Org. Chem. 2005, 9, 1315.

3. Friestad, G. K.; Mathies, A. K. Tetrahedron 2007, 63, 2541. https://doi.org/https://doi.org/10.1016/i.tet.2006.11.076

4. Kobayashi, S.; Mori, Y.; Fossey, J. S.; Salter, M. M. Chem. Rev. 2011, 111, 2626. https://doi.org/10.1021/cr100204f

5. Hartwig, J. Organotransition Metal Chemistry: From Bonding to Catalysis. University Science books: USA: 2009.

6. Layer, R. W. Chem. Rev. 1963, 63, 489. https://doi.org/10.1021/cr60225a003

7. Abbaspour Tehrani, K.; Kimpe, N. De In Science of Synthesis: Houben-Weyl Methods of Molecular Transformations; Padwa A. Ed.; Thieme Verlag: New York, 2004; Vol. 27, p 245.

8. Abbaspour Tehrani, K.; Kimpe, N. De In Science of Synthesis: Houben-Weyl Methods of Molecular Transformations; Padwa A. Ed.; Thieme Verlag: New York, 2004; Vol. 27, p. 313.

9. Cordes, E. H.; Jencks, W. P. J. Am. Chem. Soc. 1962, 84, 832. https://doi.org/10.1021/ja00864a031

10. Hine, J.; Via, F. A.; Gotkis, J. K.; Craig, J. C. J. Am. Chem. Soc. 1970, 92, 5186. https://doi.org/10.1021/ja00720a031

11. Hine, J.; Craig, J. C.; Underwood, J. G.; Via, F. A. J. Am. Chem. Soc. 1970, 92, 5194. https://doi.org/10.1021/ja00720a032

12. Godoy-Alcántar, C.; Yatsimirsky, A. K.; Lehn, J. M. J. Phys. Org. Chem. 2005, 18, 979. https://doi.org/10.1002/poc.941

13. Hall, N. E.; Smith, B. J. J. Phys. Chem. A 1998, 102, 4930.

https://doi.org/10.1021/ip9810825

14. Hall, N. E.; Smith, B. J. J. Phys. Chem. A 1998, 102, 3985. https://doi.org/10.1021/ip980627s

15. Szefczyk, B.; Kedzierski, P.; Sokalski, W. A.; Szefczyk, B. Mol. Phys. 2006, 104, 2203. https://doi.org/10.1080/00268970600654736

16. Erdtman, E.; Bushnell, E. A. C.; Gauld, J. W.; Eriksson, L. A. Comput. Theor. Chem. 2011, 963, 479. https://doi.org/https://doi.org/10.1016/i.comptc.2010.11.015

17. Berski, S.; Gordon, A. J.; Ciunik, L. Z. J. Mol. Model. 2015, 21, 57. https://doi.org/10.1007/s00894-015-2606-4

18. Ćmikiewicz, A.; Gordon, A. J.; Berski, S. Struct. Chem. 2018, 29, 243. https://doi.org/10.1007/s11224-017-1024-x

19. da Silva, P. L.; Guimaraes, L.; Pliego, J. R. J. Phys. Chem. B 2013, 117, 6487. https://doi.org/10.1021/ip311504d

20. Marenich, A. V.; Cramer, C. J.; Truhlar, D. G. J. Phys. Chem. B 2009, 113, 6378. https://doi.org/10.1021/ip810292n

21. Xu, X.; Zhang, Q.; Muller, R. P.; III, W. A. G. J. Chem. Phys. 2005, 122, 014105. https://doi.org/10.1063/1.1812257

22. Weigend, F.; Ahlrichs, R. Phys. Chem. Chem. Phys. 2005, 7, 3297. 
https://doi.org/10.1039/b508541a

23. Weigend, F. Phys. Chem. Chem. Phys. 2006, 8, 1057.

https://doi.org/10.1039/b515623h

24. Zheng, J.; Xu, X.; Truhlar, D. Theor. Chem. Acc. 2011, 128, 295.

https://doi.org/10.1007/s00214-010-0846-z

25. Zhao, Y.; Truhlar, D. G. Theor. Chem. Acc. 2008, 120, 215.

https://doi.org/10.1007/s00214-007-0310-x

26. Neese, F. Wiley Interdiscip. Rev. Comput. Mol. Sci. 2012, 2, 73.

https://doi.org/10.1002/wcms.81

27. Neese, F. Wiley Interdiscip. Rev. Comput. Mol. Sci. 2018, 8, e1327.

https://doi.org/10.1002/wcms.1327

28. Miguel, E. L. M.; Silva, P. L.; Pliego, J. R. J. Phys. Chem. B 2014, 118, 5730.

https://doi.org/10.1021/ip501379p

29. Rufino, V. C.; Pliego, J. R. Comput. Theor. Chem. 2019, 1164, 112541.

https://doi.org/https://doi.org/10.1016/i.comptc.2019.112541

30. Dalessandro, E. V.; Collin, H. P.; Guimarães, L. G. L.; Valle, M. S.; Pliego, J. R. J. Phys. Chem. B 2017, 121, 5300.

https://doi.org/10.1021/acs.jpcb.7b03191

31. Pliego, J. R.; Riveros, J. M. J. Phys. Chem. A 2001, 105, 7241.

https://doi.org/10.1021/ip004192w

32. Pliego Jr, J. R.; Riveros, J. M. Wiley Interdiscip. Rev, Comput. Mol. Sci. 2019, e1440.

https://doi.org/10.1002/WCMS.1440

33. Pliego, J. R. J. Chem. Phys. 2017, 147, 034104.

https://doi.org/10.1063/1.4993770

34. Pliego Jr., J. R.; Alcântara, A. F. d. C.; Veloso, D. P.; Almeida, W. B. d. J. Braz. Chem. Soc. 1999, $10,381$. https://doi.org/10.1590/S0103-50531999000500008

35. Rived, F.; Rosés, M.; Bosch, E. Anal. Chim. Acta 1998, 374, 309.

https://doi.org/https://doi.org/10.1016/S0003-2670(98)00418-8

36. Pliego Jr, J. R.; Riveros, J. M. Phys. Chem. Chem. Phys. 2002, 4, 1622.

https://doi.org/10.1039/b109595a 